\title{
O aparelho formal da enunciação: que aparelho é este?
}

Claudia Toldo*

\section{Resumo}

A proposta deste trabalho aborda o ensino de língua portuguesa na escola a partir de uma perspectiva enunciativa, mais precisamente, uma reflexão que proporcione ao aluno da educação básica a oportunidade de se enunciar, na e pela linguagem, e se colocar como sujeito de sua enunciação na escola enquanto espaço privilegiado para se pensar o uso da língua. Para isso, a discussão ampara-se no texto do linguista Émile Benveniste, $O$ aparelho formal da enunciação, publicado em 1970 na revista Langages, e constitutivo da segunda parte dos Problemas de linguística geral II dedicada à comunicação. Nesse artigo dirigido especificamente a linguistas, Benveniste procede a uma distinção entre $o$ emprego das formas e o emprego da língua. É essa dicotomia que justifica a necessidade de se pensar o ensino da língua a partir da enunciação, haja vista que o aluno-locutor, ao se apropriar das formas, se encontra numa relação absoluta com a escola, com a sociedade, com o mundo e, sobretudo, com uma língua que sirva para viver.

Palavras-chave: Aparelho formal da enunciação. Emprego das formas. Emprego da língua. Ensino de língua portuguesa.

\section{Considerações iniciais}

Esta pesquisa quer pensar o trabalho com o texto em sua dimensão de leitura na escola. Isso é no mínimo desafiador e instigante, uma vez que, hoje, praticamente todo professor de português fala em texto e usa textos, de diferentes gêneros, em suas aulas. Mas o que temos observado é que isso não tem trazido uma melhora significativa nem na leitura, nem na escrita dos estudantes que estão em nossas salas de aula da educação básica. Já se sabe que não há como analisar qualquer fato da língua sem considerar o funcionamento do texto/ discurso até porque as pessoas usam a língua para produzir sentido e dizer algo umas para as outras e para organizar o mundo sob seu ponto de vista. As pessoas usam a língua para ler o mundo e

Doutora em Linguística Aplicada pela Pontifícia Universidade Católica do Rio Grande do Sul, com Pós-doutorado em Linguística - estudos do texto pela Universidade Federal do Rio Grande do Sul. Professora e Coordenadora do PPGL - Doutorado e Mestrado em Letras na Universidade de Passo Fundo. Realiza pesquisas em Teorias da Enunciação, principalmente, estuda as reflexões teóricas de Émile Benveniste. Pesquisadora CNPq. E-mail: claudiast@upf.br

Data de submissão: set. 2018 - Data de aceite: dez. 2018 http://dx.doi.org/10.5335/rdes.v14i3.8607 
dizê-lo em textos. Assim, pode-se pensar que nem a língua em si mesma nem a palavra isolada nos dão sua dimensão semântica. Isso só é possível no texto. Nesse particular, a construção do sentido das palavras dá-se a partir da organização (textual) das unidades linguísticas - disponíveis na língua - colocadas em relação e em funcionamento, ou seja, é o próprio sistema de regras da língua posto em funcionamento por alguém.

Assim, essas observações se inserem na linha teórica relativa aos estudos da linguagem, especialmente na teoria enunciativa de Émile Benveniste. Esse teórico não discute diretamente a respeito da noção de texto ou de leitura ao longo de seus Problemas de Linguística Geral - ao menos não como isso é feito nos parâmetros atuais da linguística. Mas acreditamos ser possível inferir de seus trabalhos uma noção sintonizada de uso e de organização da língua em dada situação. E é em Benveniste que a escrita deste trabalho se inspira. Por isso, apoiamo-nos na ideia de que "a linguagem serve para viver" (BENVENISTE, 1967/1989, p. 222).

Interessados por "esse viver", nosso objetivo maior é realizar estudos que provoquem reflexões sobre o trabalho de leitura, enquanto possibilidade de aprendizagem da língua, na escola de educação básica.

Portanto, o objetivo principal deste estudo $^{1}$ é trazer o conceito de enunciação, concebido por Émile Benveniste, em seu texto-síntese, O Aparelho Formal da
Enunciação, e com ele e a partir dele (re) pensar as práticas escolares de leitura na sala de aula de língua portuguesa, principalmente. Junto com isso, discutir os dois conceitos trazidos por Benveniste - emprego das formas e emprego da língua -, propondo um deslocamento teórico para refletir o que significa ensinar português na escola.

\section{O Aparelho: o das formas e o da língua}

Inicio com algumas considerações, e não outras ${ }^{2}$, que entendo pertinentes para a organização de minha reflexão. Vamos a elas. O texto $O$ Aparelho Formal da Enunciação, de Émile Benveniste, publicado originalmente em 1970, na revista Langages, mais conhecido em 1974 quando publicado nos Problemas de Linguística Geral II, sintetiza $^{3}$ questões que configuram o que hoje chamamos de "Teoria da Enunciação". Obviamente que essa "Teoria" não se construiu nesse único texto, o de 70, mas foi sendo construída. Construída num tempo em que Benveniste percebeu que tudo modifica: o homem, o mundo, a língua. Um tempo (1940-1970) em que se dedicou a construir conceitos e a sintetizar, teoricamente, o que mais se colocou a observar: a língua e a linguagem humana. Texto este que, como sabemos por sermos estudiosos de Benveniste, destaca-se por reunir reflexões suas anteriores a 1970, por ser dirigido a linguistas, publicado no décimo sétimo número da revista 
Langages $^{4}$ e a pedido de Tzvetan Todorov (apenas!!!) que argumentou com Benveniste, através de uma primeira carta enviada em 1968, que não faria sentido um número da referida revista sobre enunciação sem um texto dele - afinal Benveniste estava "inaugurando" um novo campo, uma nova perspectiva de ver a língua e a linguagem. $O$ texto de 1970 também se destaca pelo impacto que causou na comunidade linguística da época- e ainda causa -, por ser o único texto (de Benveniste) que carrega - já no título - a palavra enunciação. Como foi um texto escrito para linguistas, por estar publicado na revista Langages, foi possível escolher e tratar de temas próprios e específicos do campo, questioná-los, estudá-los, mobilizando críticas e observações acerca dos estudos normalmente feitos e propondo outras visões sobre o que se estava fazendo na linguística da época. Destaca-se que Benveniste, apenas, acolheu a provocação de Todorov ${ }^{5}$. Sublinho, ainda, que, para esta reflexão que proponho hoje, a clareza e a explicitude de Benveniste em expor um conceito - o de enunciação - a partir de outra reflexão distintiva: o emprego das formas e o emprego da língua, este, para Benveniste, motivo de destaque neste texto de 1970, é de uma geniosidade que o tempo conserva.

Proponho aqui uma leitura linear do texto $O$ Aparelho porque, como já afirmei, quero trazer o conceito de enunciação com a distinção da dupla: o emprego das formas e o emprego da língua. Então, é essa leitura que se vai encontrar agora. Já no início do texto, Benveniste (1989, p. 81) pontua que "todas as nossas descrições linguísticas consagram um lugar frequentemente importante ao emprego das formas." O que isso significa? Benveniste (1989, p. 81) afirma se tratar de um "conjunto de regras fixando as condições sintáticas nas quais as formas podem ou devem normalmente aparecer, uma vez que elas pertencem a um paradigma que arrola as escolhas possíveis." Entendo que, para Benveniste (1989), é fundamental a essa discussão de 1970 trazer a diferença entre emprego das formas e emprego da língua, uma vez que ele entende este último (o emprego da língua) numa dimensão enunciativa e aquele (o emprego das formas) numa perspectiva da linguística que se fazia naquele tempo. Afirmo isso amparada no que Benveniste (1989, p. 81) defende:

Gostaríamos, contudo, de introduzir aqui uma distinção em um funcionamento que tem sido considerado somente pelo ângulo da nomenclatura morfológica e gramatical. As condições de emprego das formas não são, em nosso modo de entender, idênticas às condições de emprego da língua. São, em realidade, dois mundos diferentes, e pode ser útil insistir nesta diferença, a qual implica uma outra maneira de ver as mesmas coisas, uma outra maneira de descrever e de as interpretar.

Benveniste faz uma distinção entre as condições de emprego das formas e da língua. Diz que são "mundos diferentes" e que isso implica "uma outra maneira de ver as mesmas coisas" e salienta o que para mim, neste estudo, é primor- 
dial "uma outra maneira de descrever e de as interpretar". Sem dúvida alguma, essa diferença deve ser feita. $\mathrm{E}$ deve ser feita com o rigor que lhe é peculiar. Só gostaria de chamar a atenção, primeiramente, que esses "mundos diferentes" me parece que não são tão diferentes assim. Afinal, estamos falando de língua, esse mundo é a língua, mas o modo como a vemos é diferente. Isso é fundamental. Isso é o que traz um mundo diferente. Precisamos entender muito bem isso que diz Benveniste.

Quando Benveniste (1989) traz o emprego das formas, ele traz as relações internas da língua, as condições sintáticas, ou seja, as relações de ordem sintagmática e paradigmática da língua. Esse é o emprego das formas da língua. Conforme Flores (2013, p. 163),

[...] se restringe à investigação das regras que fixam as condições sintáticas, das possibilidades paradigmáticas, das regras de formação, das ocorrências morfológicas, das possibilidades combinatórias, entre outras relações do âmbito da forma linguística.

Sem dúvida, uma parte necessária de toda descrição linguística, uma vez que esse emprego está ligado às estruturas linguísticas, necessárias de observação a toda descrição. Aresi (2012, p. 70) afirma que

[...] "o emprego das formas" remeteria, portanto, às regras internas de formação e de emprego dos signos, os quais conferem à língua o seu caráter estrutural.

A essas regras, o próprio Benveniste (1989, p. 81), no primeiro parágrafo, já dedica um comentário:
[...] é um conjunto de regras fixando as condições sintáticas nas quais as formas podem ou devem normalmente aparecer uma vez que elas pertencem a um paradigma que arrola as escolhas possíveis.

Se voltarmos no tempo, Benveniste, em 1954, quando refletiu sobre as tendências recentes em linguística geral, fez reflexões sobre a organização interna e as leis de organização dos traços distintivos. Afirma Benveniste (1995, p. 9):

Esses elementos ordenam-se em séries e mostram em cada língua arranjos particulares. Trata-se de estrutura, em que cada peça recebe a sua razão de ser do conjunto que serve para compor.

Mais adiante, nessa mesma reflexão, ainda afirma:

Entende-se por estrutura, particularmente na Europa, o arranjo de um todo em partes e a solidariedade demonstrada entre as partes do todo, que se condicionam mutuamente [...] (BENVENISTE, 1995, p. 9).

Se quiséssemos ainda insistir no assunto, Benveniste, em 1963, no texto Vista d'olhos sobre o desenvolvimento da linguística, refletindo sobre a função da linguística, afirma: "Trata-se, com efeito, de saber em que consiste e como funciona uma língua." (1995, p. 22). E mais adiante, ratifica o que já havia dito em tempo pretérito:

[...] a língua é um arranjo sistemático de partes. Compõem-se de elementos formais articulados em combinações variáveis, segundo certos princípios variáveis, segundo certos princípios de estrutura (1995, p. 22).

O que temos aqui? Uma reflexão já anterior de que o emprego das formas da língua diz respeito ao arranjo intrín- 
seco, sintagmático e paradigmático da língua, já proposto no CLG, se podemos nos arriscar a dizer isso, sem aprofundar a questão nesse momento. Temos aqui o emprego das formas numa perspectiva da gramática da língua.

Flores (2013, p. 163), ao pontuar a diferença trazida por Benveniste ao binômio emprego das formas e emprego da língua, na seção 5.1 em que trata da enunciação: uma definição, afirma: "É sobre o emprego da língua que Benveniste constrói sua reflexão a respeito da enunciação [...]." E questiona: "que consequências é possível tirar dessa distinção à qual se liga a definição clássica da enunciação como ato individual de utilização da língua?” A partir do seu próprio questionamento, responde: "Entende-se, com isso, que ela é um ponto de vista da análise que considera o sentido, que incide em cada um dos níveis separadamente e/ou em inter-relação." E conclui: "Benveniste, assim, opera, já no início do texto, uma ruptura com uma certa visão estratificada de língua e um alargamento da análise enunciativa estendendo-a a todos os níveis da língua." Trago Flores (2013), neste início de reflexão sobre o emprego da língua, para auxiliar a elaborar minhas considerações acerca desse significativo conceito que impactou a comunidade linguística da época e continua nos tirando do lugar e nos conduzindo a olhar a língua de modo desconforme, singular, único a cada vez. Acredito que é desse lugar que um professor de língua portuguesa precisa se colocar para ensinar a língua. Acredito que não podemos esquecer o que diz o CLG:

[...] é necessário colocar-se primeiramente no terreno da língua e tomá-la como norma de todas as outras manifestações da linguagem (SAUSSURE, 2006, p. 16-17).

Mas não esquecer das manifestações da linguagem, ou seja, da língua em uso. Enfim, voltemos ao Aparelho para entender este emprego da lingua.

Ao trazer o emprego da língua, Benveniste (1989, p. 82) afirma que o "mecanismo total e constante que, de uma maneira ou de outra, afeta a língua inteira." Já de chegada, Benveniste (1989) afirma que esse mecanismo, esse aparelho, afeta não parte da língua, mas a língua inteira, toda a língua. Isso é importante, porque já temos aí uma noção de enunciação ("coisa" diferente do emprego das formas da língua). E imediatamente pontua a dificuldade:

A dificuldade é apreender este grande fenômeno, tão banal que parece confundir com a própria língua, tão necessário que nos passa despercebido (BENVENISTE, 1989, p. 82).

Isso vai nos trazer o conceito, a seguir, de enunciação: "A enunciação é este colocar em funcionamento a língua por um ato individual de utilização." Utilização de quê? Do aparelho. Do aparelho da língua que, mobilizado, constrói o aparelho da enunciação. Voltarei a isso na próxima seção.

Quando Benveniste traz o conceito de enunciação, ele chama a atenção para seu objeto de estudo à medida que trata da condição específica da enunciação. Não va- 
mos esquecer o rigor teórico do linguista, de que o artigo de 1970 foi escrito "motivado" pela carta de Todorov, pelo desafio de escrever a um público peculiar - os linguistas -, e poderíamos ainda assinalar, da importância que o campo tomava lugar. Diz Benveniste (1989, p. 82, grifo meu): "é 0 ato mesmo de produzir um enunciado, e não o texto do enunciado, que é nosso objeto." Esse ato evidencia a ação do locutor que mobiliza a língua por sua conta, ou seja, o locutor que emprega as formas da língua - 0 aparelho da língua - e com elas produz diferentes enunciações. Flores (2013) chama a atenção para as palavras ato e processo usadas por Benveniste, uma depois da outra, para dizer o que é enunciação. Vejamos o que diz o texto de 70: "Este ato é o fato do locutor que mobiliza a língua por sua conta." Em seguida: "Este grande processo pode ser estudado [...]" (BENVENISTE, 1989, p. 82). Diante dessas palavras de Benveniste, afirma Flores (2013, p. 164):

O primeiro ponto que chama a atenção aqui é o fato de Benveniste dizer que a enunciação é um grande processo, tendo, logo antes, afirmado que ela é um ato. A questão aqui é: a enunciação é um ato ou um processo? Ou ambos? É possível observar tanto o lado processual quanto o lado acional da enunciação: ela é uma porque, através dela, o locutor transforma a língua em discurso e essa transformação se dá, entre outros motivos, como um processo de agenciamento de formas e sentidos. Por isso, a enunciação comporta múltiplos aspectos.

Farei um parêntese aqui, pois os conceitos de ato e processo me são caros e entendo que preciso pensá-los simultaneamente. Ato diz respeito à relação do locutor com a língua, em dada situação comunicativa, esta sempre nova, única, singular, irrepetível; processo, algo que se renova a cada instância de discurso, quando o aparelho da língua é colocado em funcionamento. É desse processo de agenciamento de formas e sentidos que Benveniste explica três aspectos que a enunciação comporta: a) o aspecto vocal da língua, observando os sons emitidos e percebidos. Nesse aspecto, Benveniste traz a diversidade de situações nas quais uma enunciação pode ser produzida. Esse aspecto é inconcluso em Benveniste; aliás, como muitos outros elementos na teoria, mas nesse especificamente fica claro que muito há por fazer quanto ao aspecto vocal da língua. $\mathrm{O}$ próprio Benveniste, ao final do Aparelho, ressalta a necessidade de distinguir a enunciação falada da enunciação escrita, ou seja, algo resta a ser feito; b) a conversão da língua em discurso, pensando como o sentido se forma em palavras (temos aí a semantização da língua). Flores (2013, p. 165) faz um questionamento:

O que é a semantização? A definição aparentemente é textual: conversão da língua em discurso. No entanto, essa definição não parece muito distinta da definição geral de enunciação, já que converter a língua em discurso não é muito diferente de dizer que enunciar é um ato de utilizar a língua. Qual a diferença?

Sem dúvida alguma, Benveniste, nesse segundo aspecto que a enunciação comporta, chama a atenção para o fato dos procedimentos pelos quais as formas linguísticas se diversificam e se 
engendram. Chama a atenção ao fato de o locutor, ao mobilizar a língua, construir sentidos através das palavras, ou seja, semantizar a língua; c) o quadro formal de sua realização através do ato, da situação e dos instrumentos. O quadro formal de sua realização é, para Benveniste, o objeto de seu texto, ou seja, nesse texto de 1970, ele trata mesmo do quadro formal de realização da enunciação. $\mathrm{E}$ isso pauta a partir do ato individual de utilização do locutor que atualiza o aparelho da língua a cada vez que o coloca em funcionamento. Essa língua que lhe é própria desde já. Isso nos aponta um percurso "metodológico". Benveniste (1989, p. 83) afirma: "Na enunciação consideraremos, sucessivamente, o próprio ato, as situações em que ele se realiza, os instrumentos de sua realização." $\mathrm{Ou}$ seja, a partir do ato (individual do locutor que mobiliza o aparelho formal da língua), observa-se a situação em que esse ato se dá e, então, descrevem-se as formas e os recursos linguísticos que concretizaram tal enunciação. Flores (2013, p. 116) comenta:

Em outras palavras é assim que deve proceder o linguista para a análise: partir do ato, examinar a situação em que se dá esse ato e, finalmente, descrever os recursos linguísticos (os instrumentos) que tornaram possível 0 ato.

Então, poderíamos ponderar que o ato, que é individual, introduz o locutor como condição necessária para enunciação. Benveniste (1989, p. 84) pontua que antes da enunciação a língua é apenas possibilidade e depois suscita nova enunciação. E o processo, de que antes tratávamos, está justamente nesse sempre novo constituir sentido: apropriar-se do aparelho formal da língua e enunciar-se, o qual traz a posição do locutor, que implanta o outro diante de si. O locutor refere, pelo discurso, uma vez que a "referência é parte integrante da enunciação." Isso traz algo muito particular: a situação que se manifesta por um jogo de formas específicas - o aparelho formal da língua que mobilizado constrói um aparelho formal de enunciação. Esse jogo coloca o locutor em relação necessária com sua enunciação, através do emprego de formas específicas: os índices de pessoa, de ostensão e de tempo. Que se renova a cada vez. A cada tempo. A cada mobilização do aparelho formal da língua. Essa relação "necessária" acentua a relação discursiva de um locutor com seu parceiro/alocutário. Isso caracteriza a enunciação. E nessa relação discursiva encontramos os instrumentos (específicos e acessórios) que estão ligados à singularidade do locutor. Ou seja, está ligado ao que cada um, pela sua experiência de língua (por que não dizer de leitura), consegue e sabe e aprendeu mobilizar e colocar em jogo a cada enunciação.

\section{O Aparelho: um deslocamento necessário}

Esta seção intitulada O aparelho: um deslocamento necessário precisa ser lida a partir de três perspectivas: $1^{\mathrm{a}}$ ) a seção 
anterior trouxe, conscientemente, uma leitura incompleta e lacunar do texto de 1970. Trouxe apenas o que seria necessário para pontuar, nesta seção, que ora quero trazer como prospectiva de leitura desse texto em razão da pesquisa que hoje realizo; 2) todas as leituras anteriores que, automaticamente, fazemos num movimento intertextual, quando lemos Benveniste, ainda mais nesse texto de 1970 que tratei como síntese, portanto, retrospectivo, devem ser consideradas, mas impossíveis de serem assinaladas neste curto espaço comunicativo; $3^{\underline{a}}$ ) quero propor um deslocamento. Um deslocamento justamente na diferença pontual que Benveniste faz nesse célebre texto de 1970: o emprego das formas e o emprego da língua. Coaduno com todas as suas observações e todas as suas questões teóricas dedicadas à instância do homem na língua. Mas, neste momento, sinto necessidade de um deslocamento. Talvez um passo atrás, a saber: considerar os dois empregos, o das formas e o da língua, como (inter) dependentes.

Esse deslocamento se justifica, uma vez que considero que o emprego das formas se dá a partir das escolhas feitas pelo locutor que "mobiliza a língua por sua conta", evidenciando o emprego da língua inteira. Explicando melhor: essas escolhas feitas pelo locutor, que se dirige a um alocutário, trazem "um inventário" do emprego das formas e, em consequência, uma imagem da língua em emprego. Então, acredito que, pelas escolhas do locutor, temos determinados empregos das formas que sinalizam a língua (inteira, toda) em emprego.

Assim, vejo um emprego influenciando outro emprego. De que se trata aqui? Acho importante uma reflexão: o emprego das formas traz o emprego das estruturas linguísticas disponíveis na língua e o emprego da língua é o mecanismo total, o aparelho formal da língua, que reúne todos os empregos das formas que, por sua vez, afeta a língua toda, a língua inteira. Aprecio muito esse "língua toda, inteira”. Então, esse emprego das formas nos traz um locutor que mobiliza a língua por sua conta e coloca-a em funcionamento, por um ato individual de utilização. Eis o conceito de enunciação! É essa relação do locutor com a língua que determina o emprego das formas e, então, a língua em emprego.

Isso, para mim, é o significativo! É esse "mobilizar a língua por sua conta" que deve ser ensinado nas salas de aula de língua portuguesa na escola. Mas o que se pode dizer disso? Como entender essa afirmação? Acredito que, se o domínio das formas, bem como a ciência de seu funcionamento e o domínio das regras que possibilitam escolher as formas e colocá-las em uso, de tal forma que produzam sentido forem ensinadas, o locutor - nossos alunos - aprende a usá-las. O que um aluno na sala de aula em que se ensina língua portuguesa, falante nativo desta língua que está "aprendendo", precisa aprender? Precisa aprender a gramática da língua. Precisa aprender a combinar as formas da língua e construir 
sentidos com as palavras. Precisar analisar a língua em uso em dada situação comunicativa, observando os recursos empregados pelo locutor para construir tal ou tal sentido. Acredito que é necessário refletir sobre o emprego das formas, sobre as leis internas da língua, a existência e a organização das regras que, colocadas em funcionamento, trazem o emprego da língua. Destaco que o atual ensino de língua portuguesa ainda é metalinguístico, não só porque ensina nomenclaturas, mas porque traz um ensino sobre a língua; não temos um ensino linguístico da língua o qual o professor mostre aos seus alunos e faça-os refletir sobre as escolhas que um locutor faz ao colocar a língua em funcionamento. Isso não acontece na escola! $\mathbf{E}$ isso é ensinar língua!

Acredito que isso possa ser ensinado através da leitura. Aliás, ensinar a ler - para mim - é isto: ensinar a ler as estruturas da língua que foram mobilizadas por alguém, para produzir sentidos num texto que se pode ou se quer ou se necessita ler. Ler textos também faz o coração vibrar. Lembram o que dizia Sapir nas palavras iniciais? Esta é a minha hipótese: se uma língua vale a pena ser estudada, porque há textos bons para ler nessa língua, então vamos ensinar e aprender a ler. Vamos ensinar nosso aluno-locutor a refletir sobre o funcionamento da língua, analisar e entender o emprego das formas da língua, percebendo as relações linguísticas construídas pelo emprego das formas, ou seja, pelo aparelho formal da língua, para construir sentido e construir um "aparelho de enunciação" e empregar a língua toda. O professor precisa ensinar seu aluno a tornar a língua sua; a mobilizá-la por sua conta.

Portanto, acredito poder afirmar que ensinar, pela leitura de diferentes textos, a empregar as formas da língua, significa ensinar o aluno/locutor a refletir sobre o emprego dessas formas de tal maneira que encontre, no aparelho formal da língua, possibilidades combinatórias para construir sentidos outros e "afetar" a língua inteira, construindo um aparelho de enunciação. Para isso, suas experiências e práticas de leitura devem ser sempre estimuladas, sempre fomentadas na escola, sempre uteis para que se reflita a língua.

À vista disso, assumo a responsabilidade em afirmar: ensinar a ler significa ensinar a pensar sobre o aparelho formal da língua, colocado em funcionamento, $\mathrm{e}$ com ele construir um aparelho de enunciação. Aí chego ao título deste texto: O Aparelho Formal da enunciação: que aparelho é este? É o aparelho que o locutor constrói a cada vez que se enuncia. A cada vez que constrói (novos) sentidos. A cada vez que se torna sujeito de seu dizer. Portanto, o aparelho formal da língua deve ser reconhecido, compreendido, lido, apreendido nos diferentes textos usados em sala de aula, para que nossos alunos-locutores possam, a cada vez que se enunciam - e esperamos que a escola possa permitir isso cada vez mais -, construir um aparelho da enunciação 
que se renova a cada vez que se fala. A cada vez que faz vibrar o coração.

Acredito, portanto, que o aparelho formal da língua tenha de ser ensinado nas atividades de leitura realizadas na escola. Para que o aparelho formal da enunciação possa ser construído a cada enunciação de nossos alunos. Precisamos, sim, de professores que descrevam as estruturas linguísticas, ou o aparelho formal da língua, mas aproximem essa descrição da língua em uso. Caso contrário, não servirá para nada. E o pior, não se ensinará língua portuguesa na escola. Afinal, saber uma língua serve para quê? Serve para ler bons textos, como diz Sapir, ou (apenas) serve para viver, como diz Benveniste.

\section{Considerações (nunca) finais}

Finalizando, nunca definitivamente, trago Sapir (1969, p. 42):

\begin{abstract}
A linguística não oferece nem o arroubo nem o poder instrumental da matemática e também não apresenta o apelo estético universal da música, mas sob seu aspecto técnico de caranguejo a se arrastar oculta-se aquele mesmo espírito clássico, aquela mesma liberdade na contensão, que anima a matemática e a música nos seus momentos mais puros" (grifo da professora de sintaxe que hoje apresenta essas reflexões).
\end{abstract}

Portanto, apropriar-se do aparelho formal da língua (pela leitura) e construir com ela um aparelho de enunciação pode ser libertador. Pode deixar as aulas de língua portuguesa na escola mais significativas, justamente porque são significativas as descobertas dos diferentes empregos das formas e seus inteligentes arranjos combinatórios. Afinal, a língua do homem fala em palavras. Portanto elas - as palavras - precisam ser lidas, para que se compreendam as possibilidades desses arranjos combinatórios (emprego das formas), a fim de semantizá-los e afetar a língua inteira (emprego da língua), possibilitando uma verdadeira leitura de textos, para entendê-los e escrevê-los, seja como resposta a uma leitura anterior, seja como necessidade de se ser livre, porque a língua - assim - permite.

\section{The formal apparatus of enunciation: what apparatus is this?}

\begin{abstract}
The proposal of this study deals with the teaching of the Portuguese language in school from an enunciative perspective, a reflection that provides the elementar school student an opportunity to enunciate, in language and by language, and to be the subject of its own enunciation in the school as a privileged space to think the use of the language. For this, the discussion is supported by the text of the linguist Émile Benveniste, The formal apparatus of enunciation, published in 1970 in the periodic Langages, and constituted part of the Problemas de linguística geral II. In this article addressed especially to linguists, Benveniste makes a distinction between the use of forms and the use of language.
\end{abstract}


This dichotomy justifies the necessity of thinking the language teaching from an enunciative perspective given that the student-speaker, when appropriating the forms, is in an absolute relation with the school, with society, with the world and, above all, with a living language.

Keywords: Formal apparatus of enunciation. Use of forms. Use of the language. Teaching Portuguese language.

\section{Notas}

1 Este texto traz parte da minha pesquisa atual, cujo título é "Ler e escrever textos na escola: atividades, necessariamente, enunciativas", projeto de pesquisa produtividade CNPq.

2 Sugiro a leitura da Dissertação de Mestrado de Fabio Aresi. Brilhante estudo que traz uma análise minuciosa sobre $O$ Aparelho Formal da Enunciação.

3 "Sintetiza" porque tomo este texto, principalmente, como um organizador dos anteriores. Há leitores que o tomam, apenas, como prospectivo da Teoria da Enunciação.

4 Langages, Paris, Didier - Larousse, $5^{\circ}$ ano, n. 17, p. 12-18, 1970.

5 Fonds Benveniste, BnF (apud FENOGLIO, 2011, p. 275-276).

\section{Referências}

ARESI, Fábio. Síntese, organização e abertura do pensamento enunciativo de Émile Benveniste: uma exegese de O Aparelho Formal da Enunciação. 2012. Dissertação (Mestrado em Letras) - Universidade Federal do Rio Grande do Sul, Porto Alegre, 2012.

BENVENISTE, Émile. (1954). Tendências recentes em linguística geral. In:

Problemas de linguística geral I. Tradução Maria da Glória Novak e Maria Luisa Neri. Campinas, SP: Pontes, 1995. p. 3-18.
BENVENISTE, Émile. (1963). Vista d'olhos sobre o desenvolvimento da linguística. In: . Problemas de linguística geral I. Tradução Maria da Glória Novak e Maria Luisa Neri. Campinas, SP: Pontes, 1995. 19-33.

BENVENISTE, Émile. (1970). O aparelho formal da enunciação. In: . Problemas de linguística geral II. Tradução Eduardo Guimarães et al. Campinas, SP: Pontes, 1989. p. 81-90.

FLORES, Valdir do Nascimento. Introdução à teoria enunciativa de Benveniste. São Paulo: Parábola, 2013.

SAPIR, Edward. Linguística como ciência. Rio de Janeiro: Livraria Acadêmica, 1969.

SAUSSURE, Ferdinand de. Curso de linguística geral. Tradução Antônio Chelini, José Paulo Paes, Izidoro Blikstein. Organização Charles Bally, Albert Sechehaye. Colaboração de Albert Riedlinger. 27. ed. São Paulo: Cultrix, 2006. 